\title{
Intergenerational Risksharing and Equilibrium Asset Prices
}

\section{Citation}

Campbell, John Y., and Yves Nosbusch. 2007. Intergenerational risksharing and equilibrium asset prices. Journal of Monetary Economics 54, no. 8: 2251-2268.

\section{Published Version}

http://dx.doi.org/10.1016/j.jmoneco.2007.07.002

\section{Permanent link}

http://nrs.harvard.edu/urn-3:HUL.InstRepos:3196340

\section{Terms of Use}

This article was downloaded from Harvard University's DASH repository, and is made available under the terms and conditions applicable to Other Posted Material, as set forth at http:// nrs.harvard.edu/urn-3:HUL.InstRepos:dash.current.terms-of-use\#LAA

\section{Share Your Story}

The Harvard community has made this article openly available.

Please share how this access benefits you. Submit a story.

Accessibility 
NBER WORKING PAPER SERIES

\title{
INTERGENERATIONAL RISKSHARING AND EQUILIBRIUM ASSET PRICES
}

\author{
John Y. Campbell \\ Yves Nosbusch \\ Working Paper 12204 \\ http://www.nber.org/papers/w12204
}

\author{
NATIONAL BUREAU OF ECONOMIC RESEARCH \\ 1050 Massachusetts Avenue \\ Cambridge, MA 02138 \\ April 2006
}

Department of Economics, Littauer Center, Harvard University, Cambridge MA 02138, USA, and NBER. Email john_campbell@harvard.edu and nosbusch@fas.harvard.edu. This material is based upon work supported by the National Science Foundation under Grant No. 0214061 to Campbell. The views expressed herein are those of the author(s) and do not necessarily reflect the views of the National Bureau of Economic Research.

(C)2006 by John Y. Campbell and Yves Nosbusch. All rights reserved. Short sections of text, not to exceed two paragraphs, may be quoted without explicit permission provided that full credit, including $\odot$ notice, is given to the source. 
Intergenerational Risksharing and Equilibrium Asset Prices

John Y. Campbell and Yves Nosbusch

NBER Working Paper No. 12204

April 2006

JEL No. G1, H3

\begin{abstract}
In the presence of overlapping generations, markets are incomplete because it is impossible to engage in risksharing trades with the unborn. In such an environment the government can use a social security system, with contingent taxes and benefits, to improve risksharing across generations. An interesting question is how the form of the social security system affects asset prices in equilibrium. In this paper we set up a simple model with two risky factors of production: human capital, owned by the young, and physical capital, owned by all older generations. We show that a social security system that optimally shares risks across generations exposes future generations to a share of the risk in physical capital returns. Such a system reduces precautionary saving and increases the risk-bearing capacity of the economy. Under plausible conditions it increases the riskless interest rate, lowers the price of physical capital, and reduces the risk premium on physical capital.
\end{abstract}

John Y. Campbell

Morton L. and Carole S. Olshan Professor of Economics

Department of Economics

Littauer Center 213

Cambridge, MA 02138

and NBER

john campbell@ harvard.edu

Yves Nosbusch

Department of Economics

Littauer Center

Harvard University

Cambridge, MA 02138

nosbusch@fas.harvard.edu 


\section{Introduction}

The design of public pension systems is a subject of active discussion around the world. Important questions are how to combine pay-as-you-go with prefunded pension benefits, and how to adjust benefits and taxes to unanticipated shocks. Traditional public pension systems set fixed benefit rates to be financed by fixed rates of payroll taxation. Economic shocks may require adjustments in benefits, tax rates, or both, and adjustments have often been made (McHale 2001); but the nature of these adjustments is not always spelled out in advance. This lack of clarity is unfortunate, because pay-as-you-go pension systems with contingent taxes and benefits can be used to improve risksharing between generations. In effect, the government can use its powers of taxation to share capital and labor income risks across generations. Private markets cannot accomplish this because future generations are absent from the marketplace today.

Any analysis of a contingent public pension system, or contingent social security, should consider the effect of the system on private asset markets. The willingness of households to save, and to bear private investment risk, depends on their expectations about future social security payments and the correlation of these payments with risky asset returns. Thus the form of the social security system can influence the riskless interest rate and the pricing of risky assets.

To analyze such effects, we need a model with overlapping generations (OLG) in order to capture the special role of social security. Unfortunately, OLG models are hard to work with. The classic two-period OLG model of Samuelson (1958) and Diamond (1965) has inelastic supply of assets by the old (who have no reason to save), and inelastic demand for assets by the young (who have no reason to consume). A three-period extension of the model (Constantinides, Donaldson, and Mehra 2002) is more realistic, but analytically intractable. In this paper, we follow Blanchard (1985) and Gertler (1999) and use a model in which agents face a constant probability of death each period.

We simplify our analysis further by assuming fixed supplies of two assets, human capital that is owned entirely by the youngest generation alive in each period, and physical capital that is used for savings. Our assumption that physical capital cannot be accumulated is often used in the finance literature on the pricing of the aggregate equity market, following Lucas (1978) and Mehra and Prescott (1985). Following Lucas, we can think of our economy as having two "fruit trees". The first tree produces fruit that is owned by each new generation, but no single generation owns the tree itself. The second tree is owned by older generations and sold to younger ones. The assumption of fixed asset supplies means that the social security system has large effects on asset prices but no effects on asset quantities; however our model suggests the direction of quantity effects that would arise in a model with factor accumulation.

We assume that both human capital and physical capital pay risky dividends. In a laissez-faire economy, these risks are shared across generations through their effects on the equilibrium price of physical capital. Although the old do not own human capital, they are affected by a low human capital dividend because this lowers the resources of the young and thus lowers the price of physical capital that the old sell to the young. Similarly, although 
the young do not initially own physical capital, the dividend on physical capital affects the price of the capital that they buy. It turns out that in our model, the laissez-faire equilibrium shares human capital risk, but not physical capital risk, optimally between the young and the old. Thus there is a role for a contingent social security system to improve risksharing.

Some previous authors, including Shiller (1999) and Ball and Mankiw (2001), have assumed that human capital is riskless and have concentrated on the need to share physical capital risk across generations. Bohn $(2002,2003)$ points out that in a standard production model, labor income and physical capital income are proportionately exposed to technology shocks. $^{2}$ Empirical estimates of human capital risk are often quite low (Campbell, Cocco, Gomes, and Maenhout 2001), but cointegration between human and capital income could increase long-run measures of human capital risk (Benzoni, Collin-Dufresne, and Goldstein 2005). Our model justifies the concentration on physical capital risk without relying on the assumption that human capital is riskless.

\section{A Simple Model}

We assume that each period $(1-\chi)$ new agents are born and that each agent survives into the next period with probability $\chi$. This implies that there is a unit measure of agents alive in every period. Agents stay young for one period and the young generation holds all the human capital in the economy. Labor supply is inelastic and the aggregate stream of wages earned by young workers is given by $\left\{h_{t}\right\}_{t=0}^{\infty}$, where $h_{t}>0$ for all t. There are two tradable assets in the economy, riskfree one-period bonds and risky physical capital. There is a fixed supply of one unit of risky physical capital which pays a dividend stream $\left\{d_{t}\right\}_{t=0}^{\infty}$, where $d_{t}>0$ for all t. The ex-dividend unit price of physical capital is denoted by $p_{t}$.

These assumptions could be justified by a production function of the following form:

$$
Y_{t}=h_{t} H+d_{t} K, \quad \text { with } H=K=1 \text {, }
$$

where $H$ denotes aggregate human capital and $K$ the total supply of physical capital.

\section{$2.1 \quad$ Annuitization}

We assume that individual investors purchase physical capital from annuity companies which operate in a competitive market. The contract investors sign with the annuity company specifies that their physical capital holdings are taken over by the company at the time of their death. In exchange for this contingent claim, the annuity company agrees to pay them an extra income stream $\left\{A_{t}\right\}$ per unit of physical capital during their lifetime.

At the beginning of every period, a fraction $(1-\chi)$ of the population dies and is replaced by an equal measure of young agents. With homogeneous horizons, the death rates are equal at all points of the wealth distribution. This implies that, at the beginning of every

\footnotetext{
${ }^{2}$ Bohn also assumes that the price of physical capital is stable, so that the owners of physical capital have a lower overall exposure to technology shocks than the owners of human capital.
} 
period, the annuity companies are left with a fraction $(1-\chi)$ of the aggregate claims on physical capital from those who die. Given that only a measure $\chi$ of agents survive from the previous period, the total amount of annuity payments due by the annuity company at the beginning of period t equals $\chi A_{t}$. It follows that an annuity company can break even every period by offering individual investors a per period annuity payment per unit of physical capital equal to:

$$
A_{t}=\frac{1-\chi}{\chi}\left(d_{t}+p_{t}\right)
$$

in exchange for a contingent claim to their physical capital holdings in the event of their death. This multiplies the gross return on physical capital by a factor $1 / \chi$.

We also assume that individuals can use the annuity company to borrow or lend at a deterministic rate. Again, the idea is that the annuity company takes over the debt or assets of individuals when they die. With a large enough population of agents, the annuity company can break even by offering a higher rate on savings and asking for a higher rate on loans than the going riskless rate in the bond market. With a competitive market for annuities and homogeneous horizons, the gross interest rate in the annuities market $R_{a, t+1}$ is $1 / \chi$ times the gross riskless rate in the bond market $R_{f, t+1}$ :

$$
1+R_{a, t+1}=\frac{1}{\chi}\left(1+R_{f, t+1}\right) .
$$

\subsection{Laissez Faire Equilibrium}

With log utility of consumption, an agent born at date $r \leqslant t$ (and surviving up to date $\mathrm{t}$ ), maximizes the following objective function at date $t$ :

$$
E_{t}\left\{\sum_{s=0}^{\infty}(\beta \chi)^{s} \log \left(\widehat{C}_{t+s}^{r}\right)\right\},
$$

where $\widehat{C}_{t+s}^{r}$ denotes per capita consumption ${ }^{3}$ at date $t+s$ of a consumer born at date $r$.

The assumption of log utility implies that in period t, agents of any generation $r$ consume a constant fraction of their wealth at date $t$ :

$$
\widehat{C}_{t}^{r}=(1-\beta \chi) \widehat{W}_{t}^{r}
$$

where $\widehat{W}_{t}^{r}$ denotes per capita wealth in period $\mathrm{t}$ of an agent born in period $r \leqslant t$.

Summing equation (1) for all consumers alive in period t gives the following relationship between aggregate consumption and aggregate wealth:

$$
C_{t}=(1-\beta \chi) W_{t} .
$$

\footnotetext{
${ }^{3}$ We adopt the following convention throughout the paper. We denote by $\widehat{C}_{t}^{r}$ the per capita consumption in period $\mathrm{t}$ of an individual born in period $r \leqslant t$. We denote by $C_{t}^{r}$ the aggregate consumption of all the agents who were born in period $\mathrm{r}$ and who survived up to period t. Finally, $C_{t}$ denotes aggregate consumption of all agents alive in period $t$.
} 
We assume that only net output can be consumed. Then aggregate consumption needs to equal net output in equilibrium:

$$
C_{t}=Y_{t}=\left(h_{t}+d_{t}\right)
$$

Aggregate wealth of the economy is given by current output plus the ex dividend value of physical capital:

$$
W_{t}=\left(h_{t}+d_{t}\right)+p_{t}
$$

These equilibrium conditions pin down the current price of physical capital in terms of current output and parameters of the model:

$$
p_{t}=\frac{\beta \chi\left(h_{t}+d_{t}\right)}{1-\beta \chi} .
$$

The one period return on physical capital is then given by:

$$
1+R_{t+1}=\frac{d_{t+1}+p_{t+1}}{p_{t}}=\frac{\beta \chi h_{t+1}+d_{t+1}}{\beta \chi\left(h_{t}+d_{t}\right)} .
$$

These results can also be derived from equilibrium in the physical capital market. Since all consumers invest the same fraction $\alpha_{t}$ of their savings in the risky asset, the value of physical capital and aggregate wealth need to satisfy the following relationship:

$$
p_{t}=\alpha_{t}\left(\beta \chi W_{t}\right)
$$

But because physical capital is the only asset in positive net supply, we must have $\alpha_{t}=1$, which implies the solution for the physical capital price given in equation (2).

The ex dividend value of physical capital in (2) is increasing in both labor income $h_{t}$ and the physical capital dividend $d_{t}$. Labor income increases the value of physical capital by increasing the desired saving of the young, while the physical capital dividend increases it by reducing the desire of the old to sell physical capital to finance their current consumption. That is, labor income increases the demand for physical capital, while dividend income reduces the supply.

The consumption of the young and the old in the laissez faire equilibrium are given by

$$
\begin{gathered}
C_{t}^{t}=(1-\beta \chi) h_{t} \\
C_{t}^{r<t}=d_{t}+\beta \chi h_{t}=(1-\beta \chi)\left(d_{t}+p_{t}\right),
\end{gathered}
$$

where $C_{t}^{t}$ denotes the aggregate consumption of the young, that is the aggregate consumption in period $\mathrm{t}$ of all agents born in period $\mathrm{t}$, and $C_{t}^{r<t}$ denotes the aggregate consumption of the old, that is the aggregate consumption in period $\mathrm{t}$ of all agents born in periods $r<t$ and surviving up to period t.

The young consume a fraction $(1-\beta \chi)$ of their wealth $h_{t}$, and use the rest of their wealth to buy physical capital. The old consume the dividend on physical capital and the proceeds from their capital sales to the young. Equivalently, they consume a fraction $(1-\beta \chi)$ of their wealth $\left(d_{t}+p_{t}\right)$. 


\subsection{Asset Pricing Under Laissez Faire}

Aggregating over all agents alive in both periods $t$ and $t+1$ leads to a valid stochastic discount factor (SDF). This group's consumption in period t is equal to a fraction $\chi$ of aggregate consumption $C_{t}$ since only a fraction $\chi$ of all agents alive in period $\mathrm{t}$ survive into period $\mathrm{t}+1$. In period $\mathrm{t}+1$ the group's consumption is given by $C_{t+1}^{r<t+1}$ which, by definition, is the aggregate consumption at date $t+1$ of all the cohorts born before period $t+1$.

In the case of log utility, a valid SDF is therefore given by:

$$
M_{t+1}=\frac{\beta \chi C_{t}}{C_{t+1}^{r<t+1}}
$$

Using the equilibrium conditions from the previous section, the SDF simplifies to:

$$
M_{t+1}=\frac{\beta \chi\left(h_{t}+d_{t}\right)}{\beta \chi h_{t+1}+d_{t+1}}=\frac{1}{1+R_{t+1}} .
$$

This condition, that the SDF is the reciprocal of the gross return on wealth, is standard in a model with log utility. It is straightforward to check that the SDF in equation (6) is consistent with the equilibrium price for physical capital derived in equation (2):

$$
\begin{aligned}
p_{t} & =E_{t}\left[M_{t+1}\left(d_{t+1}+p_{t+1}\right)\right] \\
& =E_{t}\left[\frac{\beta \chi\left(h_{t}+d_{t}\right)}{\beta \chi h_{t+1}+d_{t+1}}\left(d_{t+1}+\frac{\beta \chi\left(h_{t+1}+d_{t+1}\right)}{1-\beta \chi}\right)\right] \\
& =\frac{\beta \chi\left(h_{t}+d_{t}\right)}{1-\beta \chi}
\end{aligned}
$$

The riskless rate in the laissez faire economy is given by:

$$
\frac{1}{1+R_{f, t+1}}=E_{t}\left[M_{t+1}\right]=E_{t}\left(\frac{1}{1+R_{t+1}}\right) \text {. }
$$

\section{Social Security}

\subsection{Risk Exposures Under Laissez Faire}

Expected lifetime utility of an agent of generation $t$, by which we mean an agent born at the beginning of period $t$, is given by:

$$
\widehat{U}_{t}^{t} \equiv E_{t}\left\{\sum_{s=0}^{\infty}(\beta \chi)^{s} \log \left(\widehat{C}_{t+s}^{t}\right)\right\} .
$$

As before, hats denote per capita variables and time superscripts index an agent's generation. In period $t$, there is a measure $(1-\chi)$ of agents of generation $t$, a measure $\chi(1-\chi)$ of agents of generation $t-1$, a measure $\chi^{2}(1-\chi)$ of agents of generation $t-2$, and so on. 
The first thing to note is that all generations have some exposure to both human capital risk and physical capital dividend risk in the laissez faire equilibrium. In particular, young agents are exposed to dividend risk indirectly through the price of physical capital, which determines the share of physical capital they can acquire with their savings. More formally, agents of generation $t$ have a deterministic per capita labor income of $\frac{h_{t}}{1-\chi}$ in the first period of their life but no initial claims to physical capital. With log utility, they consume a fraction $(1-\beta \chi)$ of their wealth:

$$
\widehat{C}_{t}^{t}=(1-\beta \chi) \widehat{W}_{t}^{t}=(1-\beta \chi) \frac{h_{t}}{1-\chi}
$$

The remainder of their wealth is invested in physical capital. The fraction of aggregate physical capital $\hat{\theta}_{t}^{t}$ an agent of generation t acquires depends on the price of physical capital in period $t$ :

$$
\widehat{\theta}_{t}^{t}=\frac{\beta \chi \widehat{W}_{t}^{t}}{p_{t}}=\frac{1-\beta \chi}{1-\chi} \frac{h_{t}}{h_{t}+d_{t}} .
$$

A high dividend in period $t$ has a negative effect on the expected lifetime utility of agents of generation $t$ because it results in a higher physical capital price, which reduces the amount of physical capital that these agents can acquire with their initial savings. High labor income has an intuitive positive effect on the expected lifetime utility of the agents who earn it.

Older cohorts are exposed indirectly to human capital risk through its effects on the price of physical capital and thereby on the returns on their savings. The purpose of the remainder of this section is to derive precise expressions for the exposures of the different cohorts to the two types of risk in this economy. In the Appendix we show that, for an agent of generation $t$, expected lifetime utility at the beginning of period $t$ is given by:

$$
\begin{aligned}
\widehat{U}_{t}^{t} & =\frac{1}{1-\beta \chi} \log \left(\widehat{C}_{t}^{t}\right)-\frac{\beta \chi}{1-\beta \chi} \log \left(h_{t}+d_{t}\right)+\varphi_{t} \\
& =\frac{1}{1-\beta \chi} \log \frac{1-\beta \chi}{1-\chi}+\frac{1}{1-\beta \chi} \log \left(h_{t}\right)-\frac{\beta \chi}{1-\beta \chi} \log \left(h_{t}+d_{t}\right)+\varphi_{t},
\end{aligned}
$$

where $^{4}$

$$
\varphi_{t}=E_{t} \sum_{s=1}^{\infty}(\beta \chi)^{s} \log \left\{\frac{1}{\chi^{s}}\left[\prod_{r=1}^{s-1} \frac{\beta \chi h_{t+r}+d_{t+r}}{h_{t+r}+d_{t+r}}\right]\left(\beta \chi h_{t+s}+d_{t+s}\right)\right\} .
$$

Agents of any generation $r<t$ also consume a constant fraction of their wealth in period $\mathrm{t}$ :

$$
\widehat{C}_{t}^{r}=(1-\beta \chi) \widehat{W}_{t}^{r}=(1-\beta \chi) \widehat{\theta}_{t-1}^{r} \frac{1}{\chi}\left(d_{t}+p_{t}\right)=\widehat{\theta}_{t-1}^{r} \frac{1}{\chi}\left(\beta \chi h_{t}+d_{t}\right)
$$

where $\widehat{\theta}_{t-1}^{r}$ denotes the share of physical capital brought forward from period t-1 by an agent born at date $r$. The factor $\frac{1}{\chi}$ is due to the fact that consumers purchase the physical capital from annuity companies in a competitive market.

\footnotetext{
${ }^{4}$ In general, the parameter $\varphi_{t}$ is time dependent due to potential persistence in the dividend process. In the special case of i.i.d. dividends, $\varphi_{t}$ is constant.
} 
The remainder is invested in physical capital. The share of physical capital acquired in period $t$ by an agent of generation $\mathrm{r}$ is:

$$
\widehat{\theta}_{t}^{r}=\frac{\beta \chi \widehat{W}_{t}^{r}}{p_{t}}=\frac{1}{\chi} \frac{\beta \chi h_{t}+d_{t}}{h_{t}+d_{t}} \widehat{\theta}_{t-1}^{r} .
$$

The expected lifetime utility at the beginning of period $t$ for an agent of generation $r<t$ is given by:

$$
\begin{aligned}
\widehat{U}_{t}^{r} & =\frac{1}{1-\beta \chi} \log \left(\widehat{C}_{t}^{r}\right)-\frac{\beta \chi}{1-\beta \chi} \log \left(h_{t}+d_{t}\right)+\varphi_{t} \\
& =\frac{1}{1-\beta \chi} \log \widehat{\theta}_{t-1}^{r}+\frac{1}{1-\beta \chi} \log \frac{1}{\chi}\left(\beta \chi h_{t}+d_{t}\right)-\frac{\beta \chi}{1-\beta \chi} \log \left(h_{t}+d_{t}\right)+\varphi_{t} .
\end{aligned}
$$

The four terms in this expression may be interpreted as follows. The first term is a function of the state variable $\widehat{\theta}_{t-1}^{r}$ which gives the share of physical capital acquired in the previous period by an agent of generation $r<t$. It incorporates the effects of all past shocks since the birth of generation $r$ and up to period $t-1$ on the expected lifetime utility of the agent. The second term gives the effect of the current shocks $h_{t}$ and $d_{t}$ on the unit value of physical capital holdings (inclusive of annuity payments) brought forward from last period. Agents of generation $r$ consume a constant fraction of their wealth during period $t$ and reinvest the rest in physical capital. The amount of physical capital they can buy to carry forward into period $t+1$ depends negatively on the current price of physical capital and thus on current output. This effect is captured by the third term and could be described as reinvestment risk. Finally, the last term measures the expected effect of future output realizations on lifetime utility. This term is identical for all generations. The $\frac{1}{1-\beta \chi}$ factors multiplying these terms arise because the effects on consumption are permanent.

Equation (8) shows that agents of all generations born before the current period have exactly the same exposure of expected lifetime utility to current shocks. Furthermore, comparing equations (7) and (8), one can see that agents of all generations are exposed to the same reinvestment risk. Hence the only difference in exposure to current shocks across the different generations arises from different exposures of period $t$ wealth to contemporaneous realizations of $h_{t}$ and $d_{t}$.

$>$ From this argument it also follows that, in order to share the exposure to $h_{t}$ and $d_{t}$ equally among all agents, it is sufficient to have a tax-transfer system that equalizes the sensitivity of current wealth, and hence current consumption, to $h_{t}$ and $d_{t}$ across agents.

\subsection{First Best Intergenerational Consumption Allocation}

Suppose that the social planner designs a social security system behind a Rawlsian veil of ignorance. The purpose of the social security system is to allocate net output optimally between the different cohorts alive in any given period. We assume that the planner places equal weight on the welfare of all agents. The first order conditions of the planner's problem imply that the expected consumption path of any individual should decline at rate $\beta$, conditional on survival of the agent. Given that only a fraction $\chi$ of any cohort survives into 
the next period, this implies the following optimal consumption allocations for the different cohorts:

$$
\begin{gathered}
C_{t}^{t}=(1-\beta \chi)\left(h_{t}+d_{t}\right) \\
C_{t}^{r}=(1-\beta \chi)(\beta \chi)^{t-r}\left(h_{t}+d_{t}\right), \text { for } r<t,
\end{gathered}
$$

where $C_{t}^{r}$ denotes aggregate consumption in period t of the cohort born in period r. Aggregating over all the old cohorts, the solution to the social planner's problem calls for dividing net output in each period between the young and old cohorts according to the following fractions:

$$
\begin{gathered}
C_{t}^{t}=(1-\beta \chi)\left(h_{t}+d_{t}\right) \\
C_{t}^{r<t}=\beta \chi\left(h_{t}+d_{t}\right) .
\end{gathered}
$$

Comparing this to the consumption allocations in the decentralized equilibrium,

$$
\begin{gathered}
C_{t}^{t}=(1-\beta \chi) h_{t} \\
C_{t}^{r<t}=\beta \chi h_{t}+d_{t},
\end{gathered}
$$

shows that the optimal policy in this economy calls for a net wealth transfer of $d_{t}$ from the old to the young in each period, contrary to what we usually think of as a social security system. This comparison also highlights the fact that human capital risk is shared optimally in the laissez faire equilibrium. The old already hold the optimal exposure to human capital risk indirectly through the price of physical capital.

\section{3 "Second Best" with Full Risksharing}

In order to distinguish between redistribution of the average physical capital dividend and reallocation of physical capital risk, we now write the physical capital dividend as

$$
d_{t}=\mu_{d t}+\varepsilon_{t}
$$

where $\mu_{d t}=E_{t-1}\left(d_{t}\right)$ and $\varepsilon_{t}$ is the pure risk component of the dividend on physical capital. We assume that $\varepsilon_{t}$ is independent and identically distributed over time.

Suppose that, instead of implementing the first best consumption allocation, the social planner only partially reallocates the mean consumption level between generations but still tries to achieve the optimal allocation of consumption risk:

$$
\begin{gathered}
C_{t}^{t}=(1-\beta \chi)\left(h_{t}+\varepsilon_{t}\right)+(1-\theta) \mu_{d t} \\
C_{t}^{r<t}=\beta \chi\left(h_{t}+\varepsilon_{t}\right)+\theta \mu_{d t},
\end{gathered}
$$

where $\theta>\beta \chi$, with $\theta=\beta \chi$ corresponding to the first best consumption allocation. This setup allows for deterministic transfers from old to young $(\theta<1)$ or from young to old 
$(\theta>1)^{5}$. The knife-edge case of $\theta=1$ corresponds to "pure risksharing". In the pure risksharing equilibrium, the desired consumption allocations are given by:

$$
\begin{gathered}
C_{t}^{t}=(1-\beta \chi)\left(h_{t}+\varepsilon_{t}\right) \\
C_{t}^{r<t}=\beta \chi\left(h_{t}+\varepsilon_{t}\right)+\mu_{d t} .
\end{gathered}
$$

We require the aggregate payroll tax on the young $T_{t}$ to equal the aggregate social security payouts to all old cohorts $S_{t}$, so that the system is balanced each period. In the presence of social security, the expected lifetime wealth of agents includes expected future social security transfers. The anticipated transfer stream accruing to the cohort that is young in period $t$ is given by:

$$
\left\{-T_{t},(1-\beta \chi) S_{t+1},(1-\beta \chi) \beta \chi S_{t+2},(1-\beta \chi)(\beta \chi)^{2} S_{t+3}, \ldots \ldots\right\} .
$$

The value of this expected income stream in period t may be written as:

$$
-T_{t}+(1-\beta \chi) z_{t}
$$

where $z_{t}$ is the value of the following stream of payments:

$$
\left\{S_{t+1}, \beta \chi S_{t+2},(\beta \chi)^{2} S_{t+3}, \ldots \ldots\right\} .
$$

Similarly, the value of present and future social security transfers to those who are old in period t may be written as:

$$
S_{t}+\beta \chi z_{t}
$$

$z_{t}$ can be interpreted as the present value of future social security payouts accruing to all generations currently alive.

The correct measure of wealth in the presence of social security incorporates anticipated future payouts:

$$
\begin{aligned}
W_{t}^{t} & =\left[h_{t}-T_{t}+(1-\beta \chi) z_{t}\right] \\
W_{t}^{r<t} & =\left[d_{t}+p_{t}+S_{t}+\beta \chi z_{t}\right] .
\end{aligned}
$$

With log utility, individual optimization implies that consumption is a constant fraction of wealth:

$$
\begin{aligned}
C_{t}^{t} & =(1-\beta \chi)\left[h_{t}-T_{t}+(1-\beta \chi) z_{t}\right] \\
C_{t}^{r<t} & =(1-\beta \chi)\left[d_{t}+p_{t}+S_{t}+\beta \chi z_{t}\right] .
\end{aligned}
$$

It is easy to verify that the following transfer policy implements the social planner's consumption allocations in equation (10):

$$
T_{t}=S_{t}=\mu_{d t} \frac{\theta-\beta \chi}{1-\beta \chi}+\beta \chi h_{t}-(1-\beta \chi)\left(d_{t}+p_{t}\right)
$$

\footnotetext{
${ }^{5}$ In order to rule out the possibility of negative consumption in some states of the world for either age group, we assume that the human dividend process has a lower bound $\underline{h}>\mu_{d t}$ and we restrict the range of the deterministic part of the transfer to $\beta \chi<\theta<\beta \chi+(1-\beta \chi) \frac{h}{\mu_{d t}}$.
} 


\subsection{Asset Pricing in the Presence of Social Security}

In the presence of a social security system, the SDF is given by:

$$
M_{t+1}^{s}=\frac{\beta \chi C_{t}}{C_{t+1}^{r<t+1}}=\frac{\beta \chi\left(h_{t}+d_{t}\right)}{(1-\beta \chi)\left[d_{t+1}+p_{t+1}+S_{t+1}+\beta \chi z_{t+1}\right]}
$$

When social security takes the particular form assumed in the previous section, the expression for the SDF simplifies to:

$$
M_{t+1}^{s}=\frac{\beta \chi\left(h_{t}+d_{t}\right)}{\beta \chi\left(h_{t+1}+\varepsilon_{t+1}\right)+\theta \mu_{d t+1}}=\frac{h_{t}+d_{t}}{h_{t+1}+\frac{\theta \mu_{d t+1}}{\beta \chi}+\varepsilon_{t+1}}
$$

In the presence of social security, aggregate consumption in period $t$ is given by:

$$
\begin{aligned}
C_{t} & =C_{t}^{t}+C_{t}^{r<t} \\
& =(1-\beta \chi)\left[h_{t}-T_{t}+(1-\beta \chi) z_{t}\right]+(1-\beta \chi)\left[d_{t}+p_{t}+S_{t}+\beta \chi z_{t}\right] \\
& =(1-\beta \chi)\left[h_{t}+d_{t}+p_{t}+z_{t}\right] .
\end{aligned}
$$

Aggregate consumption needs to equal net output in equilibrium:

$$
C_{t}=Y_{t}=h_{t}+d_{t} .
$$

This equilibrium condition pins down the sum of the aggregate ex dividend value of physical capital and expected future social security payouts accruing to those currently alive:

$$
p_{t}+z_{t}=\frac{\beta \chi\left(h_{t}+d_{t}\right)}{1-\beta \chi} .
$$

The stochastic discount factor for general social security derived in equation (13) should price physical capital and the social security payout stream $\left\{S_{t+1}, \beta \chi S_{t+2},(\beta \chi)^{2} S_{t+3}, \ldots \ldots.\right\}$ :

$$
\begin{gathered}
p_{t}=E_{t}\left[M_{t+1}^{s}\left(d_{t+1}+p_{t+1}\right)\right] \\
z_{t}=E_{t}\left[M_{t+1}^{s}\left(S_{t+1}+\beta \chi z_{t+1}\right)\right]
\end{gathered}
$$

It is easy to check that $M_{t+1}^{s}$ is consistent with the equilibrium condition (15):

$$
\begin{aligned}
p_{t}+z_{t} & =E_{t}\left[M_{t+1}^{s}\left(d_{t+1}+p_{t+1}+S_{t+1}+\beta \chi z_{t+1}\right)\right] \\
& =E_{t}\left[\frac{\beta \chi\left(h_{t}+d_{t}\right)}{(1-\beta \chi)\left[d_{t+1}+p_{t+1}+S_{t+1}+\beta \chi z_{t+1}\right]}\left(d_{t+1}+p_{t+1}+S_{t+1}+\beta \chi z_{t+1}\right)\right] \\
& =\frac{\beta \chi\left(h_{t}+d_{t}\right)}{1-\beta \chi} .
\end{aligned}
$$




\subsection{Effect of Social Security on the Riskless Rate of Interest}

The simple expressions for the SDF in the two economies derived in equations (6) and (14) provide a direct way of assessing the effect of different social security arrangements on the riskless rate of interest. In what follows, $\rho_{h d}$ denotes the correlation between the human and physical capital dividends. The variances of the innovations to the human and physical dividend processes are denoted by $\sigma_{h}^{2}$ and $\sigma_{d}^{2}$.

Proposition 1a In the case of deterministic dividends to human capital, a pure risksharing social security policy unambiguously increases the riskless rate of interest. For $\theta=1$ and $\sigma_{h}^{2}=0, R_{f, t+1}^{s}>R_{f, t+1}^{l f}$.

In the case of stochastic dividends to human capital, a pure risksharing social security policy increases the riskless rate of interest provided that the dividends to human and physical capital are positively correlated. For $\theta=1$ and $\sigma_{h}^{2}>0, R_{f, t+1}^{s}>R_{f, t+1}^{l f}$ if $\rho_{h d} \geq 0$.

Proof. See Appendix.

The intuition for this effect is that pure risksharing social security is a form of insurance whereby all future generations effectively hedge some of the rate of return risk on the savings of those cohorts that are currently alive. As a result, those currently alive have a reduced need for precautionary savings. Given that the riskless asset is in zero net supply in this economy, the equilibrium riskless rate needs to rise in order to clear the bond market.

The condition $\rho_{h d} \geq 0$ is sufficient for this result to hold, but is stronger than necessary. A necessary and sufficient condition derived in the Appendix is that $\frac{\sigma_{d}}{\sigma_{h}}>-\rho_{h d} \frac{2 \beta \chi}{1+\beta \chi}$. Note that this will hold if human capital is sufficiently safe relative to physical capital. To understand this condition, consider what happens if it fails. If the two dividends are negatively correlated $\left(\rho_{h d}<0\right)$ and the human capital dividend is riskier than the physical capital dividend $\left(\sigma_{h}>\sigma_{d}\right)$, the old bear too little consumption risk under laissez faire. In this case physical capital is a valuable hedge against human capital risk and the first best policy increases the consumption risk of the old by giving future young generations the benefit of this hedge. But this perverse case is unlikely to be empirically relevant, since estimates of the correlation between human and physical capital risk tend to be positive (Benzoni, Collin-Dufresne, and Goldstein 2005).

Proposition 1b The effect of a purely deterministic transfer stream from the young to the old is to increase the riskless rate of interest. The opposite is true of a deterministic transfer stream from the old to the young.

Proof. See Appendix.

Under a purely deterministic transfer $\tau$, the consumption of the old and the young are given by

$$
\begin{gathered}
C_{t}^{t}=(1-\beta \chi) h_{t}-\tau \\
C_{t}^{r<t}=\beta \chi h_{t}+d_{t}+\tau,
\end{gathered}
$$

where $\tau>0$ implies a net transfer from young to old and $\tau<0$ a net transfer from old to young $^{6}$. The allocation of risk is identical to the decentralized equilibrium.

\footnotetext{
${ }^{6}$ In order to rule out the possibility of negative values of consumption in some states of the world for
} 
A deterministic transfer scheme from the young to the old in all future periods reduces the need to save for those who are currently alive. In order for the bond market to clear, the equilibrium riskless interest rate needs to rise. The opposite holds for a deterministic transfer from the old to the young.

\subsection{Effect of Social Security on the Price of Physical Capital}

The SDF derived in equation (14) can be used to solve explicitly for the price of physical capital in the equilibrium with social security. Details are given in the Appendix. In the case of i.i.d. dividends $\left(\mu_{d t}=\mu_{d}\right.$ for all $\left.t\right)$, the price of physical capital in the presence of social security is equal to a constant multiple of the price under laissez faire:

$$
p_{t}^{s}=F p_{t}^{l f},
$$

where an explicit expression for the constant $F$ is given in the Appendix. Depending on the form of the social security system, this factor F can be smaller or larger than one. The next two propositions give more precise conditions.

Proposition 2a In the case of deterministic dividends to human capital and i.i.d. dividends to physical capital, a pure risksharing social security policy $(\theta=1)$ unambiguously leads to a fall in the price of physical capital $(\mathrm{F}<1)$.

In the case of i.i.d. dividends to human capital and i.i.d. dividends to physical capital, a pure risksharing social security policy leads to a fall in the price of physical capital provided that $\operatorname{Cov}_{t}\left[d_{t+1}, \frac{1}{h_{t+1}+d_{t+1}+\frac{1-\beta \chi}{\beta \chi} \mu_{d}}\right]<0$.

Proof. See Appendix.

As noted in the previous section, a pure risksharing social security system reduces the need for precautionary savings by those currently alive. The only savings vehicle available in this economy is the risky physical capital asset. Since physical capital is in fixed supply, this reduction in demand results in a lower equilibrium price.

The covariance condition for Proposition 2a holds unambiguously when human capital dividends are deterministic. It also holds for the particular stochastic processes we consider for human capital dividends in our calibration exercise.

Proposition $2 \mathbf{b}$ The effect of a deterministic transfer stream from the young to the old is to decrease the price of physical capital. The opposite is true of a deterministic transfer stream from the old to the young.

Proof. See Appendix.

As in the previous section, these effects may be interpreted as the result of changes in savings needs of those currently alive.

Equation (15) provides an alternative way of stating the intuition for these effects. The sum $\left(p_{t}+z_{t}\right)$ takes the same value irrespective of the particular form of the social security

either of the two age groups, we assume that the transfer is in the range $-\beta \chi \underline{h}<\tau<(1-\beta \chi) \underline{h}$. 
system. A pure risksharing policy means that social security is valuable, implying a positive value for $z_{t}$ and therefore a lower physical capital price $p_{t}$ compared to laissez faire. The same is true of a social security system that consists of deterministic transfers from the young to the old.

\subsection{Effect of Social Security on the Return on Physical Capital}

In the presence of social security and when dividends are i.i.d., the rate of return on physical capital is given by:

$$
1+R_{t+1}^{s}=\frac{h_{t+1}+\frac{1+F \beta \chi-\beta \chi}{F} \frac{d_{t+1}}{\beta \chi}}{h_{t}+d_{t}} .
$$

Proposition 3 When dividends are i.i.d., $E_{t}\left(1+R_{t+1}^{s}\right)>E_{t}\left(1+R_{t+1}^{l f}\right)$ iff $F<1$ and $\operatorname{Var}_{t}\left(1+R_{t+1}^{s}\right)>\operatorname{Var}_{t}\left(1+R_{t+1}^{l f}\right)$ iff $F<1$.

Proof. See Appendix.

If the price of physical capital falls, its average return increases but its volatility also increases because the volatile current dividend has a larger proportional impact on the return. This result implies that a pure risksharing social security system leads to an increase in the expected rate of return on physical capital as well as an increase in its return volatility compared to the laissez faire equilibrium. A deterministic transfer from the young to the old has the same qualitative effects, while a deterministic transfer from the old to the young reduces expected returns and return volatilities on the risky asset.

\subsection{Effect of Social Security on the Risk Premium}

There are two offsetting effects on the risk premium on physical capital. A pure risksharing social security system improves the allocation of risk in the economy. This results in a higher overall riskbearing capacity. A way to see this is to look at the portfolios of investors in the two economies. In the presence of social security, investors effectively hold an implicit second asset (their claim to future social security benefits) in their portfolio. By design, this second asset hedges the returns on the original asset (physical capital) held in the portfolio. This makes investors less averse to the risk on the physical capital asset, thereby reducing the risk premium they demand in equilibrium. There is however an offsetting effect. As the previous section has demonstrated, a pure risksharing social security also increases the return volatility of the risky asset, which, by itself, would tend to increase the risk premium.

In our numerical analysis we find that, for all empirically plausible parameter values, the first effect dominates and the risk premium on physical capital falls as a result of introducing a pure risksharing social security system. ${ }^{7}$

\footnotetext{
${ }^{7}$ We can find counterexamples but they are somewhat artificial. In particular, if the physical capital dividend is lognormally distributed with low mean and high volatility (e.g. $\mu_{d}=0.1, \sigma_{d}=0.5$ ), it is possible for the risk premium to increase. This counterexample works with a deterministic human capital dividend $\left(\mu_{h}=1, \sigma_{h}=0\right)$. However, the implied return volatilities on the risky asset are implausibly high, on the
} 


\section{Calibrating the Model}

We interpret one period to last for twenty years. We set the survival probability $\chi$ equal to $2 / 3$. This implies an expected economic lifetime of sixty years. The idea is that economic life starts at around age twenty, there is an initial period of twenty years where agents earn labor income, followed on average by two twenty year periods of financing consumption through savings. The discount factor $\beta$ is set to 0.96 on an annual basis.

For the purpose of the simulations, we assume i.i.d. lognormal processes. The mean of the human capital dividend $\mu_{h}$ is normalized to one. We set the mean of the physical capital dividend $\mu_{d}$ equal to $1 / 2$ in order to match the relative magnitudes of capital and labor shares in national income for the United States. The standard deviation of the human capital dividend $\sigma_{h}$ is set to 0.1 and we assume a correlation of 0.5 between human and physical capital dividends at the 20 year horizon ${ }^{8}$. We report results for several values of the standard deviation of the physical capital dividend; $\sigma_{d}$ ranges from 0 to 0.12 . These parameter values imply that the endogenous volatility of the return on physical capital is in a range between 0 and 35 per cent on an annual basis. In our figures, all variables are plotted against the volatility of returns on physical capital.

Figure 1 plots the riskless interest rate in the laissez faire and pure risksharing equilibria. It confirms the result in Proposition 1 that a shift to a pure risksharing social security system increases the riskless interest rate. The corresponding change in the risk premium on physical capital is plotted in Figure 2. For our range of parameter values, the risk premium always falls as a result of pure risksharing. The effect of increased riskbearing capacity thus dominates the effect of the increased return volatility. Indeed, Figure 3 shows that the increase in the volatility of returns on physical capital is relatively modest. We should also note that the risk premia predicted by our model are generally much lower than those observed empirically. This is a manifestation of the familiar equity premium puzzle. It arises here in part because of our assumption of log utility and the low associated coefficient of relative risk aversion. Figure 4 illustrates the fact that the price of physical capital is lower under pure risksharing, as shown in Proposition 2.

\section{Conclusion}

In this paper we have studied the effects of government intergenerational transfers on asset prices. Real-world social security systems can be interpreted as combinations of deterministic transfers from young to old, and contingent transfers that enable young and old to share their income risks. We have shown that both elements of social security systems have similar effects on asset prices. They reduce life-cycle and precautionary savings motives, and thus increase the riskless interest rate and lower the price of physical capital. The lower price for

order of $100 \%$ on an annual basis.

${ }^{8}$ In order to rule out the possibility of negative values of consumption for the young under pure risksharing, we assume that $h_{t}$ follows the following process: $h_{t}=\mu_{d}+z$, where $\mathrm{z}$ is distributed lognormally with mean $\left(\mu_{h}-\mu_{d}\right)$ and standard deviation $\sigma_{h}$. This specification implies a lower bound on the human capital dividend of $\underline{h}=\mu_{d}$. 
physical capital increases the expected return on capital, but also increases the volatility of that return because volatile dividends have a larger proportional impact. The effect on the risk premium is theoretically ambiguous; on the one hand the riskbearing capacity of the economy increases when risks are better shared across generations, but on the other hand the return risk of physical capital is greater. In realistic examples the former effect dominates, and social security reduces the risk premium for physical capital.

We have derived these results using a stylized model in which physical capital cannot be accumulated. A natural extension of our approach would allow capital accumulation. Social security would then have smaller effects on asset prices, but would lower the capital stock in long-run equilibrium. If risky and riskless capital could be separately accumulated, our results suggest that social security systems would have a milder negative effect on the accumulation of risky capital because the increased riskbearing capacity of the economy partially offsets the effect of reduced saving.

All these results apply in reverse if we consider recent proposals to reduce intergenerational transfers and encourage private retirement saving. These proposals have the potential to increase overall capital accumulation and drive down interest rates, but if they reduce intergenerational risksharing the increased saving may be disproportionately directed towards safe assets in which case the equity premium may increase. 


\section{Appendix}

\section{Derivation of risk exposures under laissez faire}

It is easy to derive closed form relationships relating the share of physical capital holdings, consumption and wealth of an agent of generation $t$ in all future periods to dividend realizations since the time of birth and parameters of the model. The share of physical capital holdings purchased in period $t+s$, conditional on survival, is given by the following recursive formula:

$$
\begin{aligned}
\widehat{\theta}_{t+s}^{t} & =\frac{\beta \chi \widehat{W}_{t+s}^{t}}{p_{t+s}} \\
& =\frac{\beta \chi \widehat{\theta}_{t+s-1}^{t}\left(p_{t+s}+d_{t+s}+A_{t+s}\right)}{p_{t+s}} \\
& =\frac{\beta \chi \widehat{\theta}_{t+s-1}^{t} \frac{1}{\chi}\left(p_{t+s}+d_{t+s}\right)}{p_{t+s}} \\
& =\frac{1}{\chi} \frac{\beta \chi h_{t+s}+d_{t+s}}{h_{t+s}+d_{t+s}} \widehat{\theta}_{t+s-1}^{t},
\end{aligned}
$$

or, by iterated substitution,

$$
\widehat{\theta}_{t+s}^{t}=\frac{1-\beta \chi}{1-\chi} \frac{h_{t}}{h_{t}+d_{t}} \frac{1}{\chi^{s}} \prod_{r=1}^{s} \frac{\beta \chi h_{t+r}+d_{t+r}}{h_{t+r}+d_{t+r}} .
$$

Expressions for wealth and consumption of an agent of generation $t$ in period $t+s$ are given by:

$$
\widehat{W}_{t+s}^{t}=\frac{\widehat{\theta}_{t+s}^{t} p_{t+s}}{\beta \chi}=\frac{1}{1-\chi} \frac{h_{t}}{h_{t}+d_{t}} \frac{1}{\chi^{s}}\left[\prod_{r=1}^{s-1} \frac{\beta \chi h_{t+r}+d_{t+r}}{h_{t+r}+d_{t+r}}\right]\left(\beta \chi h_{t+s}+d_{t+s}\right),
$$

and

$$
\widehat{C}_{t+s}^{t}=(1-\beta \chi) \widehat{W}_{t+s}^{t}=\frac{1-\beta \chi}{1-\chi} \frac{h_{t}}{h_{t}+d_{t}} \frac{1}{\chi^{s}}\left[\prod_{r=1}^{s-1} \frac{\beta \chi h_{t+r}+d_{t+r}}{h_{t+r}+d_{t+r}}\right]\left(\beta \chi h_{t+s}+d_{t+s}\right),
$$

or in terms of period $t$ consumption:

$$
\widehat{C}_{t+s}^{t}=\frac{\widehat{C}_{t}^{t}}{h_{t}+d_{t}} \frac{1}{\chi^{s}}\left[\prod_{r=1}^{s-1} \frac{\beta \chi h_{t+r}+d_{t+r}}{h_{t+r}+d_{t+r}}\right]\left(\beta \chi h_{t+s}+d_{t+s}\right)
$$

Expected utility of period $t+s$ consumption is related to period $t$ consumption by the following relation:

$$
E_{t} \log \left(\widehat{C}_{t+s}^{t}\right)=\log \left(\widehat{C}_{t}^{t}\right)-\log \left(h_{t}+d_{t}\right)+E_{t} \log \left\{\frac{1}{\chi^{s}}\left[\prod_{r=1}^{s-1} \frac{\beta \chi h_{t+r}+d_{t+r}}{h_{t+r}+d_{t+r}}\right]\left(\beta \chi h_{t+s}+d_{t+s}\right)\right\}
$$


In fact, for agents of any generation $r \leq t$, and for any $s>0$ :

$$
\begin{aligned}
E_{t} \log \left(\widehat{C}_{t+s}^{r}\right) & =\log \left(\widehat{C}_{t}^{r}\right)-\log \left(h_{t}+d_{t}\right)+E_{t} \log \left\{\frac{1}{\chi^{s}}\left[\prod_{r=1}^{s-1} \frac{\beta \chi h_{t+r}+d_{t+r}}{h_{t+r}+d_{t+r}}\right]\left(\beta \chi h_{t+s}+d_{t+s}\right)\right\} \\
& =\log \left(\widehat{C}_{t}^{r}\right)-\log \left(h_{t}+d_{t}\right)+\varphi_{s t},
\end{aligned}
$$

where $\varphi_{s t}$ is a common constant for all generations. From this it follows that expected lifetime utility, as of the beginning of period $t$, of agents of any generation $r \leq t$ is given by:

$$
\begin{aligned}
\widehat{U}_{t}^{r} & \equiv E_{t}\left\{\sum_{s=0}^{\infty}(\beta \chi)^{s} \log \left(\widehat{C}_{t+s}^{r}\right)\right\} \\
& =\log \left(\widehat{C}_{t}^{r}\right)+\sum_{s=1}^{\infty}(\beta \chi)^{s} E_{t} \log \left(\widehat{C}_{t+s}^{r}\right) \\
& =\log \left(\widehat{C}_{t}^{r}\right)+\sum_{s=1}^{\infty}(\beta \chi)^{s}\left[\log \left(\widehat{C}_{t}^{r}\right)-\log \left(h_{t}+d_{t}\right)+\varphi_{s t}\right] \\
\widehat{U}_{t}^{r} & =\frac{1}{1-\beta \chi} \log \left(\widehat{C}_{t}^{r}\right)-\frac{\beta \chi}{1-\beta \chi} \log \left(h_{t}+d_{t}\right)+\varphi_{t},
\end{aligned}
$$

where $\varphi_{t}=\sum_{s=1}^{\infty}(\beta \chi)^{s} \varphi_{s t}$ is a common constant for all generations.

For an agent of generation $t$ :

$$
\widehat{C}_{t}^{t}=(1-\beta \chi) \frac{h_{t}}{1-\chi}
$$

so that expected lifetime utility at the beginning of period $t$ is given by equation (7):

$$
\widehat{U}_{t}^{t}=\frac{1}{1-\beta \chi} \log \frac{1-\beta \chi}{1-\chi}+\frac{1}{1-\beta \chi} \log \left(h_{t}\right)-\frac{\beta \chi}{1-\beta \chi} \log \left(h_{t}+d_{t}\right)+\varphi_{t}
$$

For any generation $r<t$ :

$$
\widehat{C}_{t}^{r}=(1-\beta \chi) \widehat{\theta}_{t-1}^{r} \frac{1}{\chi}\left(d_{t}+p_{t}\right)=\widehat{\theta}_{t-1}^{r} \frac{1}{\chi}\left(\beta \chi h_{t}+d_{t}\right)
$$

so that expected lifetime utility at the beginning of period $t$ is given by equation (8):

$$
\widehat{U}_{t}^{r}=\frac{1}{1-\beta \chi} \log \widehat{\theta}_{t-1}^{r}+\frac{1}{1-\beta \chi} \log \frac{1}{\chi}\left(\beta \chi h_{t}+d_{t}\right)-\frac{\beta \chi}{1-\beta \chi} \log \left(h_{t}+d_{t}\right)+\varphi_{t} .
$$




\section{Proof of Proposition 1a}

Noting that,

$$
\begin{gathered}
\frac{1}{1+R_{f, t+1}}=E_{t}\left[M_{t+1}\right], \\
R_{f, t+1}^{s}>R_{f, t+1}^{l f} \text { iff } E_{t}\left[M_{t+1}^{s}\right]<E_{t}\left[M_{t+1}^{l f}\right] .
\end{gathered}
$$

By Jensen's inequality, this condition is equivalent to:

$$
\operatorname{Var}_{t}\left[h_{t+1}+\frac{\mu_{d t+1}}{\beta \chi}+\varepsilon_{t+1}\right]<\operatorname{Var}_{t}\left[h_{t+1}+\frac{\mu_{d t+1}}{\beta \chi}+\frac{\varepsilon_{t+1}}{\beta \chi}\right],
$$

which says that the denominator of the SDF in the decentralized equilibrium is a meanpreserving spread of the denominator of the SDF under pure risksharing social security. This last condition is clearly satisfied in the case of deterministic dividends to human capital since $\beta \chi<1$.

In the case of stochastic dividends to human capital, the condition can be rewritten as

$$
\frac{\sigma_{d}}{\sigma_{h}}>-\rho_{h d} \frac{2 \beta \chi}{1+\beta \chi}
$$

Hence a sufficient condition in the case of stochastic dividends to human capital is that $\rho_{h d} \geq 0$.

\section{Proof of Proposition 1b}

With a purely deterministic social security transfer, the SDF is given by:

$$
M_{t+1}^{s}=\frac{h_{t}+d_{t}}{h_{t+1}+\frac{d_{t+1}}{\beta \chi}+\frac{\tau}{\beta \chi}} .
$$

Comparing this expression to the SDF under laissez-faire,

$$
M_{t+1}^{l f}=\frac{h_{t}+d_{t}}{h_{t+1}+\frac{d_{t+1}}{\beta \chi}}
$$

shows that:

$$
E_{t}\left[M_{t+1}^{s}\right]<E_{t}\left[M_{t+1}^{l f}\right] \text { iff } \tau>0
$$

\section{Derivation of the price of physical capital with social security}

We can use the SDF in the presence of social security to price physical capital:

$$
p_{t}^{s}=E_{t}\left[M_{t+1}^{s}\left(d_{t+1}+p_{t+1}\right)\right] \text {. }
$$

Substituting in the expression for the SDF:

$$
p_{t}^{s}=E_{t}\left[\frac{h_{t}+d_{t}}{h_{t+1}+\frac{\theta \mu_{d t+1}}{\beta \chi}+\varepsilon_{t+1}}\left(d_{t+1}+p_{t+1}\right)\right] .
$$


Iterating forward:

$$
p_{t}^{s}=\left(h_{t}+d_{t}\right) E_{t}\left\{\begin{array}{c}
\frac{d_{t+1}}{h_{t+1}+\frac{\theta \mu_{d t+1}}{\beta \chi}+\varepsilon_{t+1}} \\
\left.+\frac{1}{h_{t+1}+\frac{\theta \mu_{d}}{\beta \chi}+\varepsilon_{t+1}} E_{t+1}\left[\frac{h_{t+1}+d_{t+1}}{h_{t+2}+\frac{\theta \mu_{d t+2}}{\beta \chi}+\varepsilon_{t+2}}\left(d_{t+2}+E_{t+2}[\ldots .]\right)\right]\right\} .
\end{array}\right.
$$

By the law of iterated expectations:

$$
p_{t}^{s}=\left(h_{t}+d_{t}\right)\left\{\begin{array}{c}
E_{t}\left[\frac{d_{t+1}}{h_{t+1}+\frac{\theta \mu_{d t+1}}{\beta \chi}+\varepsilon_{t+1}}\right] \\
+E_{t}\left[\frac{h_{t+1}+d_{t+1}}{h_{t+1}+\frac{\theta \mu_{d t+1}}{\beta \chi}+\varepsilon_{t+1}} \frac{d_{t+2}}{h_{t+2}+\frac{\theta \mu_{d t+2}}{\beta \chi}+\varepsilon_{t+2}}\right] \\
+E_{t}\left[\frac{h_{t+1}+d_{t+1}}{h_{t+1}+\frac{\theta \mu_{d t+1}}{\beta \chi}+\varepsilon_{t+1}} \frac{h_{t+2}+d_{t+2}}{h_{t+2}+\frac{\theta \mu_{d t+2}}{\beta \chi}+\varepsilon_{t+2}} \frac{d_{t+3}}{h_{t+3}+\frac{\theta \mu_{d t+3}}{\beta \chi}+\varepsilon_{t+3}}\right]+\ldots
\end{array}\right\},
$$

or

$$
p_{t}^{s}=\left(h_{t}+d_{t}\right) E_{t}\left\{\sum_{s=1}^{\infty}\left[\prod_{r=1}^{s-1} \frac{h_{t+r}+d_{t+r}}{h_{t+r}+\frac{\theta \mu_{d t+r}}{\beta \chi}+\varepsilon_{t+r}}\right] \frac{d_{t+s}}{h_{t+s}+\frac{\theta \mu_{d t+s}}{\beta \chi}+\varepsilon_{t+s}}\right\} .
$$

This is a closed form solution for the price of physical capital in terms of parameters of the model, current realizations of $h_{t}$ and $d_{t}$, and expected future realizations of $h_{t}$ and $d_{t}$.

The assumption of i.i.d. dividends leads to a particularly simple form since it implies that, for any $r \geq 1$ :

$$
\begin{aligned}
& E_{t}\left[\frac{h_{t+r}+d_{t+r}}{h_{t+r}+\frac{\theta \mu_{d}}{\beta \chi}+\varepsilon_{t+r}}\right]=E_{t}\left[\frac{h_{t+1}+d_{t+1}}{h_{t+1}+\frac{\theta \mu_{d}}{\beta \chi}+\varepsilon_{t+1}}\right] \equiv E_{1} \\
& E_{t}\left[\frac{d_{t+r}}{h_{t+r}+\frac{\theta \mu_{d}}{\beta \chi}+\varepsilon_{t+r}}\right]=E_{t}\left[\frac{d_{t+1}}{h_{t+1}+\frac{\theta \mu_{d}}{\beta \chi}+\varepsilon_{t+1}}\right] \equiv E_{2} .
\end{aligned}
$$

Rewriting the expression for $E_{1}$ as:

$$
\begin{aligned}
E_{1} & =E_{t}\left[\frac{h_{t+1}+d_{t+1}}{h_{t+1}+\frac{\theta \mu_{d}}{\beta \chi}+\varepsilon_{t+1}}\right] \\
& =E_{t}\left[\frac{h_{t+1}+d_{t+1}}{h_{t+1}+d_{t+1}+\left(\frac{\theta}{\beta \chi}-1\right) \mu_{d}}\right] \\
& =1-E_{t}\left[\frac{\left(\frac{\theta}{\beta \chi}-1\right) \mu_{d}}{h_{t+1}+d_{t+1}+\left(\frac{\theta}{\beta \chi}-1\right) \mu_{d}}\right],
\end{aligned}
$$

shows that $E_{1}<1^{9}$ iff $\theta>\beta \chi^{10}$.

\footnotetext{
${ }^{9}$ We only consider strictly positive dividend processes.

${ }^{10}$ The limit case $\theta=\beta \chi$ corresponds to the first best consumption allocation. The land price goes to infinity in this case.
} 
sion:

Under this condition the price of physical capital is finite, given by the following expres-

$$
\begin{aligned}
p_{t}^{s} & =\left(h_{t}+d_{t}\right)\left\{E_{2}+E_{2} E_{1}+E_{2}\left(E_{1}\right)^{2} \ldots\right\} \\
& =\left(h_{t}+d_{t}\right) \frac{E_{2}}{1-E_{1}} .
\end{aligned}
$$

The price of physical capital in the presence of social security is thus equal to a constant fraction of the price under laissez faire:

$$
p_{t}^{s}=F p_{t}^{l f}
$$

where

$$
F \equiv \frac{E_{2}}{1-E_{1}} \frac{1-\beta \chi}{\beta \chi}
$$

\section{Proof of Proposition 2a}

In the case where $\theta=1$, the expression for $\mathrm{F}$ may be rewritten:

$$
F=\frac{E_{t}\left[\frac{d_{t+1}}{h_{t+1}+d_{t+1}+\frac{1-\beta \chi}{\beta \chi} \mu_{d}}\right]}{E_{t}\left[\frac{\mu_{d}}{h_{t+1}+d_{t+1}+\frac{1-\beta \chi}{\beta \chi} \mu_{d}}\right]}
$$

or,

$$
F=1+\frac{\operatorname{Cov}_{t}\left[d_{t+1}, \frac{1}{h_{t+1}+d_{t+1}+\frac{1-\beta \chi}{\beta \chi}} \mu_{d}\right.}{E_{t}\left[\frac{\mu_{d}}{h_{t+1}+d_{t+1}+\frac{1-\beta \chi}{\beta \chi} \mu_{d}}\right]} .
$$

Note that $\lim _{\sigma_{d}^{2} \rightarrow 0} F=1$. More generally, the expectation term in the denominator is positive since dividends are positive by assumption. Hence:

$$
F<1 \text { iff } \operatorname{Cov}_{t}\left[d_{t+1}, \frac{1}{h_{t+1}+d_{t+1}+\frac{1-\beta \chi}{\beta \chi} \mu_{d}}\right]<0 .
$$

This condition holds unambiguously in the special case when the human capital dividend is deterministic $\left(h_{t+1}=h\right)$. Indeed, in this case:

$$
\begin{aligned}
\operatorname{Cov}_{t}\left[d_{t+1}, \frac{1}{h+d_{t+1}+\frac{1-\beta \chi}{\beta \chi} \mu_{d}}\right] & =\operatorname{Cov}_{t}\left[h+d_{t+1}+\frac{1-\beta \chi}{\beta \chi} \mu_{d}, \frac{1}{h+d_{t+1}+\frac{1-\beta \chi}{\beta \chi} \mu_{d}}\right] \\
& =1-E_{t}\left[h+d_{t+1}+\frac{1-\beta \chi}{\beta \chi} \mu_{d}\right] E_{t}\left[\frac{\mu_{d}}{h+d_{t+1}+\frac{1-\beta \chi}{\beta \chi} \mu_{d}}\right] \\
& <0,
\end{aligned}
$$

by Jensen's inequality. 
For stochastic human capital dividends on the other hand, we need to impose that:

$$
\operatorname{Cov}_{t}\left[d_{t+1}, \frac{1}{h_{t+1}+d_{t+1}+\frac{1-\beta \chi}{\beta \chi} \mu_{d}}\right]<0
$$

for the result to hold.

\section{Proof of Proposition 2b}

With a purely deterministic social security transfer, the expressions for $E_{1}$ and $E_{2}$ are modified as follows:

$$
\begin{aligned}
& E_{1}=E_{t}\left[\frac{h_{t+1}+d_{t+1}}{h_{t+1}+\frac{d_{t+1}}{\beta \chi}+\frac{\tau}{\beta \chi}}\right] \\
& E_{2}=E_{t}\left[\frac{d_{t+1}}{h_{t+1}+\frac{d_{t+1}}{\beta \chi}+\frac{\tau}{\beta \chi}}\right] .
\end{aligned}
$$

In this case, the expression for $\mathrm{F}$ can be rewritten as:

$$
\frac{1}{F}=1+\frac{\tau}{1-\beta \chi} \frac{E_{t}\left[\frac{1}{h_{t+1}+\frac{d_{t+1}}{\beta \chi}+\frac{\tau}{\beta \chi}}\right]}{E_{t}\left[\frac{d_{t+1}}{h_{t+1}+\frac{d_{t+1}}{\beta \chi}+\frac{\tau}{\beta \chi}}\right]}
$$

The two expectations in this expressions are positive since dividends are positive by assumption and the expression in the denominator of the expectations is a scalar multiple of the consumption of the old age group, which is positive as long as $-\beta \chi \underline{h}<\tau<(1-\beta \chi) \underline{h}$ (the restriction on transfers discussed in the main text).

Hence $F<1$ iff $\tau>0$, which means that transfer is from the young to the old.

\section{Proof of Proposition 3}

Note that the return on physical capital in the presence of social security may be rewritten:

$$
1+R_{t+1}^{s}=\frac{1}{h_{t}+d_{t}}\left[h_{t+1}+\left(1+\frac{1-\beta \chi}{F \beta \chi}\right) d_{t+1}\right] .
$$

Hence $\frac{\partial E_{t}\left(R_{t+1}^{s}\right)}{\partial F}<0$ and $\frac{\partial \operatorname{Var}_{t}\left(R_{t+1}^{s}\right)}{\partial F}<0$. Noting that $\lim _{F \rightarrow 1} R_{t+1}^{s}=R_{t+1}^{l f}$ completes the proof. 


\section{References}

Abel, Andrew, 2003, "The Effects of a Baby Boom on Stock Prices and Capital Accumulation in the Presence of Social Security," Econometrica, 71, 551-578.

Ball, Laurence and N. Gregory Mankiw, 2001, "Intergenerational Risk Sharing in the Spirit of Arrow, Debreu and Rawls, with Applications to Social Security Design," NBER Working Paper No. 8270.

Benzoni, Luca, Pierre Collin-Dufresne, and Robert S. Goldstein, 2005, "Portfolio Choice over the Life Cycle in the Presence of 'Trickle-Down' Labor Income", NBER Working Paper No. 11247.

Blanchard, Olivier J., 1985, "Debt, Deficits, and Finite Horizons", Journal of Political Economy 93, 223-247.

Bohn, Henning, 2002, "Retirement Savings in an Aging Society: A Case for Innovative Government Debt Management", in Alan Auerbach and Heinz Herrman eds., Ageing, Financial Markets and Monetary Policy, Springer, Berlin.

Bohn, Henning, 2003, "Intergenerational Risksharing and Fiscal Policy", unpublished paper, University of California Santa Barbara.

Campbell, John Y., Joao Cocco, Francisco Gomes, and Pascal Maenhout, 2001, "Investing Retirement Wealth: A Life-Cycle Model", in John Y. Campbell and Martin Feldstein eds., Risk Aspects of Investment-Based Social Security Reform, University of Chicago Press, Chicago, IL.

Campbell, John Y. and Luis M. Viceira, 2002, Strategic Asset Allocation: Portfolio Choice for Long-Term Investors, Oxford University Press, New York, NY.

Constantinides, George, John B. Donaldson, and Rajnish Mehra, 2002, “Junior Can’t Borrow: A New Perspective on the Equity Premium Puzzle", Quarterly Journal of Economics 117, 269-296.

Diamond, Peter A., 1965, "National Debt in a Neoclassical Growth Model", American Economic Review 55, 1126-1150.

Farmer, Roger E. A., 2002, "Fiscal Policy, Equity Premia and Heterogeneous Agents", unpublished paper, UCLA.

Gertler, Mark, 1999, "Government Debt and Social Security in a Life-Cycle Economy", Carnegie-Rochester Conference Series on Public Policy 50, 61-110.

Lucas, Robert E., Jr., 1978, "Asset Prices in an Exchange Economy", Econometrica 46, 1429-1446.

McHale, John, 2001, "The Risk of Social Security Benefit-Rule Changes: Some International Evidence", in John Y. Campbell and Martin Feldstein eds., Risk Aspects of InvestmentBased Social Security Reform, University of Chicago Press, Chicago, IL. 
Mehra, Rajnish and Edward C. Prescott, 1985, "The Equity Premium: A Puzzle", Journal of Monetary Economics 15, 145-161.

Samuelson, Paul A., 1958, "An Exact Consumption-Loan Model of Interest With and Without the Social Contrivance of Money", Journal of Political Economy 66, 467482 .

Shiller, Robert J., 1999, "Social Security and Institutions for Intergenerational, Intragenerational, and International Risk Sharing", Carnegie-Rochester Conference Series on Public Policy 50, 165-204.

Viceira, Luis M., 2001, "Optimal Portfolio Choice for Long-Horizon Investors with Nontradable Labor Income", Journal of Finance 56, 433-470. 
Figure 1: Riskless rate (in basis points, beta $=0.96$ )

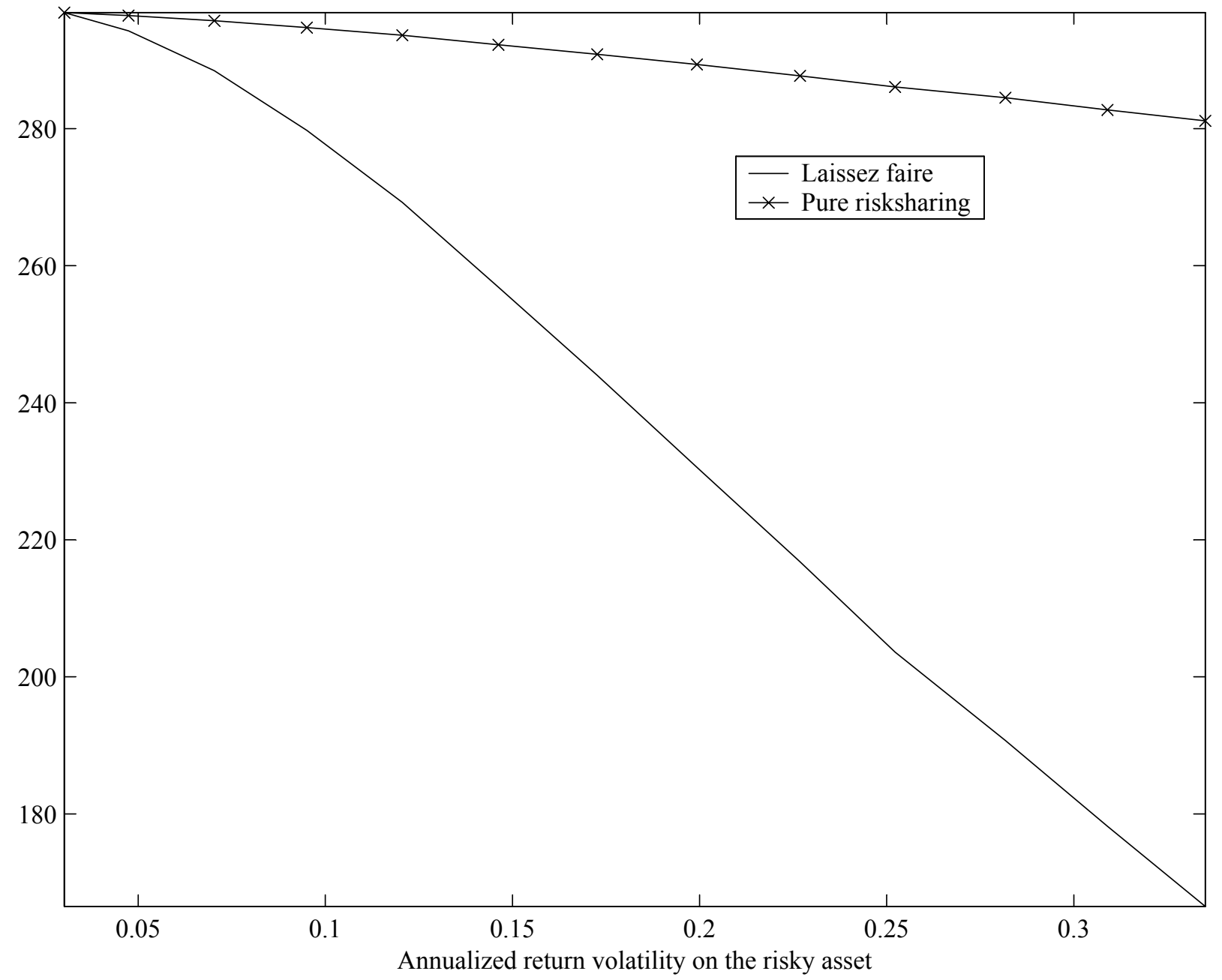


Figure 2: Risk premium (in basis points, beta $=0.96$ )

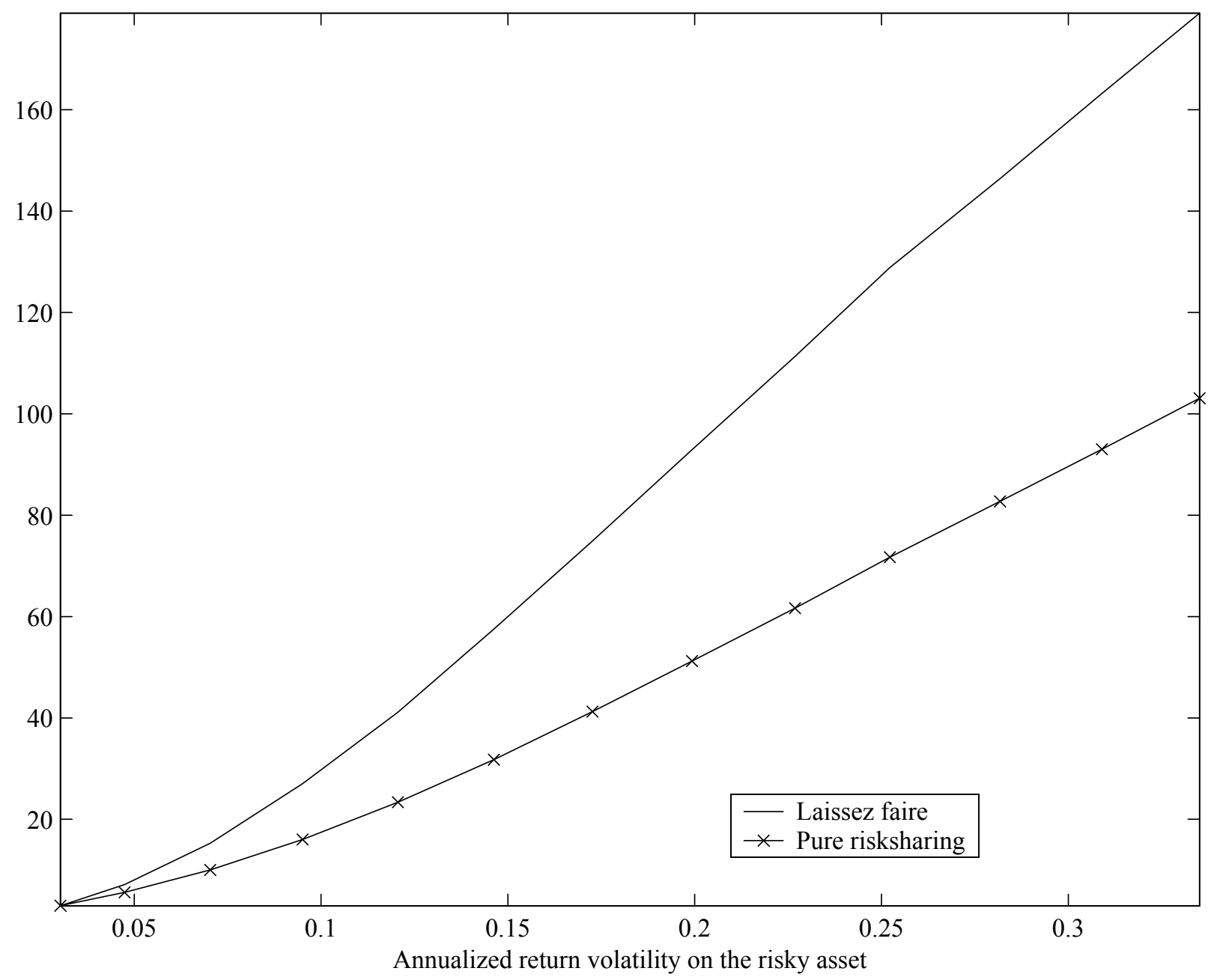


Figure 3: Annualized return volatility (beta $=0.96$ )

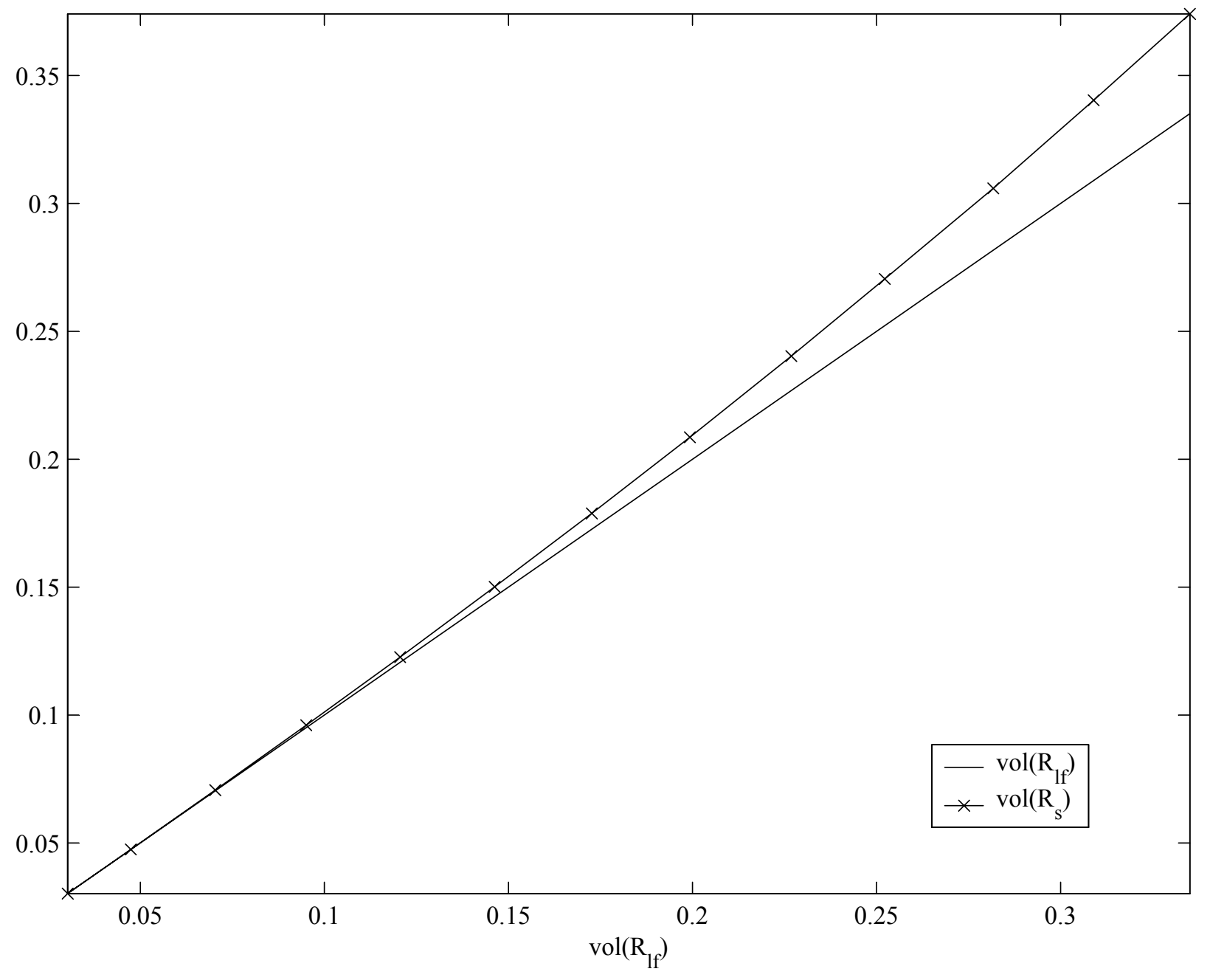


Figure 4: Ratio of physical capital prices (beta $=0.96$ )

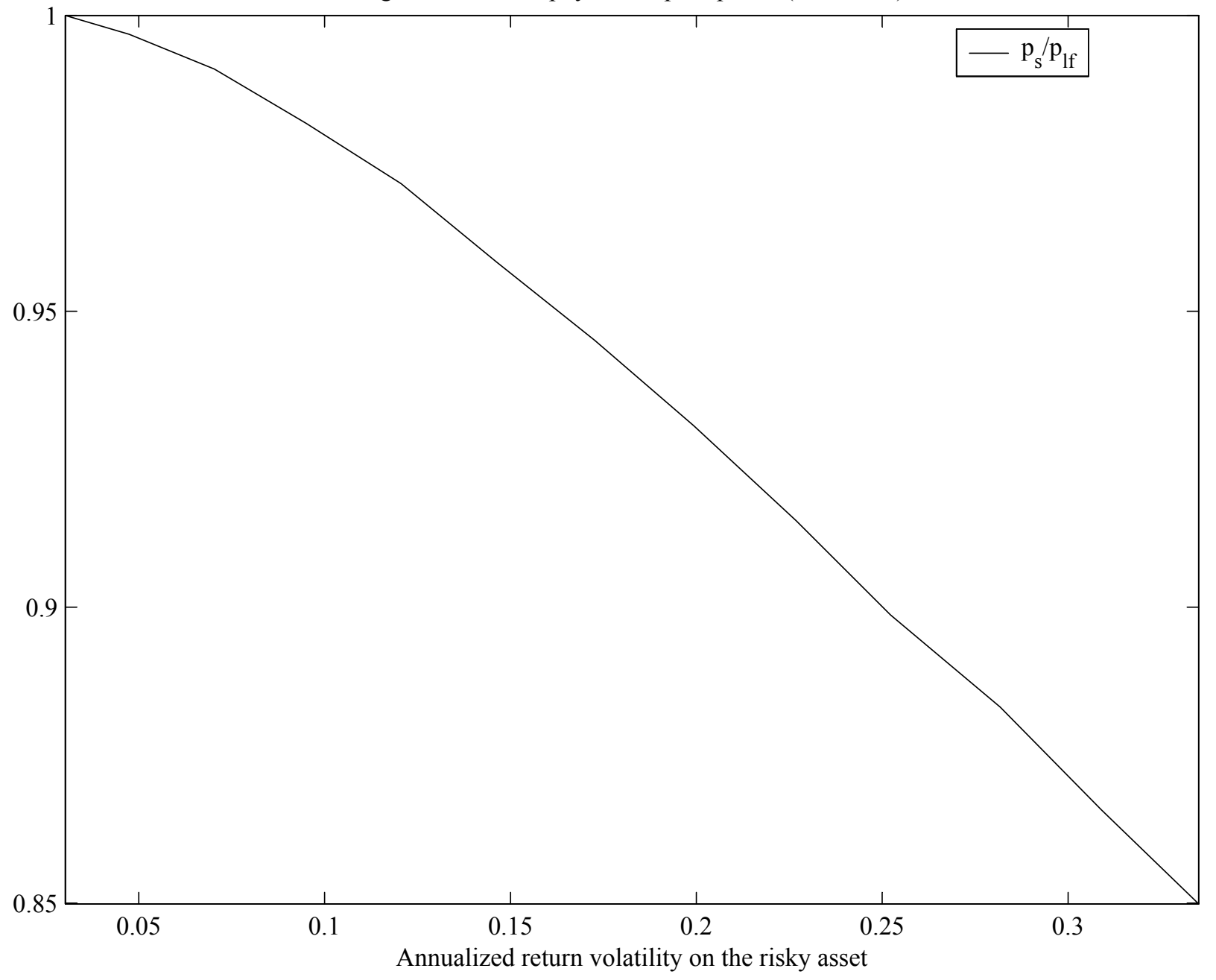

